GEOLOGICAL SURVEY CIRCULAR 591

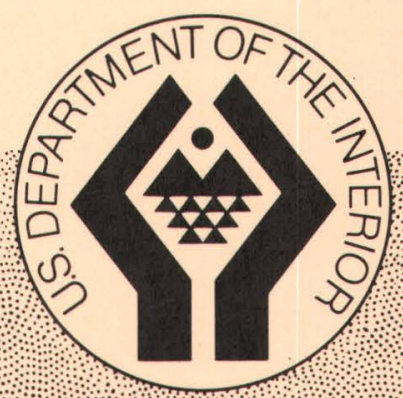

Direct-Current Arc and

Alternating-Current Spark

Emission Spectrographic

Field Methods for the

Semiquantitative Analysis

of Geologic Materials 

Direct-Current Arc and

Alternating-Current Spark

Emission Spectrographic

Field Methods for the

Semiquantitative Analysis

of Geologic Materials

By D. J. Grimes and A. P. Marranzino

GEOLOGICAL SURVEY CIRCULAR 591

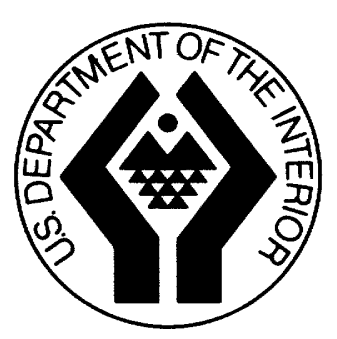


United States Department of the Interior STEWART L. UDALL, Secretary

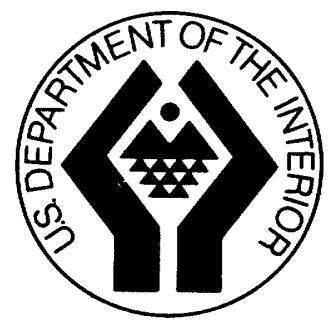

Geological Survey

William T. Pecora, Director 


\section{CONTENTS}

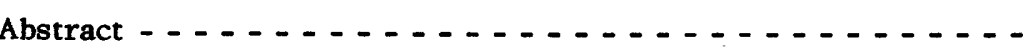

Introduction - . - . $-\ldots \ldots \ldots$

Equipment - . . . . . . . . . . . . - $\ldots \ldots$

Direct-current arc method _. . . . . . . . . . . . . .

Preparation of matrix for standards - . . . . . . . . .

Preparation of field standards _ . . . . . . . . . . . .

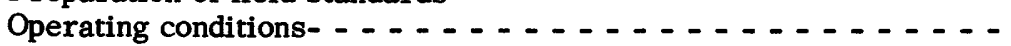

Analytical procedure . . . . . . . . . . . . . .

Alternating-current spark method- . . . . . . . . . . . .

Preparation of matrix solution for standards . . . . . . . . .

Preparation of standard solutions- . . . . . . . . . . .

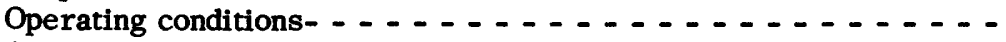

Analytical procedure _... - . . . . . . . . . . .

Conclusions - . . . . . . . . . . . . . . . . -

References - ..........................

Page

Rerences

\section{ILLUSTRATION}

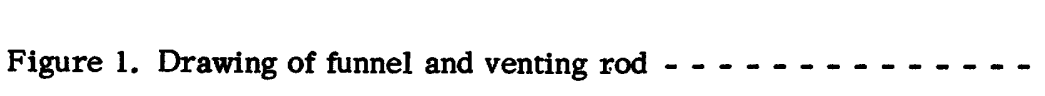

Page

\section{TABLES}

Table 1. Matrix used in direct-current arc method - . . . . -

2. Concentrations of elements in Field Standard I - . . - . -

3. Dilution chart-three-step standards _. - . . . . . . -

4. Concentrations of elements in Field Standard II _. . . . -

5. Limits of determination-direct-current arc method - - - -

6. Matrix solution-alternating-current spark method- - - - -

7. Standard solutions-alternating-current spark method - . - -

8. Limits of determination-alternating-current spark method . . . . . . . . . . . . . . . . . . 


\title{
Direct-Current Arc and Alternating-Current Spark Emission Spectrographic Field Methods for the Semiquantitative Analysis of Geologic Materials
}

\author{
By D. J. Grimes and A. P. Marranzino
}

\begin{abstract}
Two spèctrographic methods are used in mobile field laboratories of the U. S. Geological Survey. In the direct-current arc method, the ground sample is mixed with graphite powder, packed into an electrode crater, and burned to completion. Thirty elements are determined. In the spark method, the sample, ground to pass a 150-mesh screen, is digested in hyr ofluoric acid followed by evaporation to dryness and dissolution in aqua regia. The solution is fed into the spark gap by means of a rotating-disk electrode arrangement and is excited with an alternating-current spark discharge. Fourteen elements are determined. In both techniques, light is recorded on Spectrum Analysis No. 1, 35-millimeter film, and the spectra are compared visually with those of standard films.
\end{abstract}

\section{INTRODUCTION}

Data on the trace element content of geologic materials has increasingly greater application in geochemical reconnais sance and in studies of oreweathering processes. S e m i qua n t i t a t i ve spectrographic methods provide a rapid and economic means for acquiring such information.

In the early 1950's the U.S. Geological Survey designed and tested a mobile spectrographic laboratory and established the feasibility of using rapid semiquantitative methods in the field (Canney and others, 1957). Initially, analytical procedures were similar to those described by Myers, Canney, and Dunton (1956). Subsequently, the techniques were improved as described by Oda, Myers, and Cooley (1958). With the implementation of the Heavy Metals program, it became necessary to increase the number of elements determined and to modify existing procedures so that lower concentrations of elements such as silver, gold, bismuth, cadmium, cobalt, copper, palladium, platinum, and antimony could be measured.

\section{EQUIPMENT}

Spectrograph: 1.5-meter Wadsworth-mounted, having a dispersion of 5.45 A (angstrom units) per millimeter over the spectral range from $2,100 \mathrm{~A}$ to 4,800 $A$ in the second order.

Source:

Direct-current arc -220 volts with maximum arc current of 15 amperes; control of arc current is maintained by resistances in series.
Alternating-current spark-18,000 rms (root mean square) volts; output of 10 amperes RF (radio frequency) modulated with a 0.005 microfarad condenser at 310 microhenrys of inductance and residual resistance.

Slit width: 10 microns.

Comparator: X 20 magnification.

Upper electrode: Preformed graphite $1 / 8$ inch in diameter with an $8^{\circ}$ taper.

Lower electrode:

Direct-current arc-preformed graphite 1/4 inch in diameter with a crater wall thickness of 0.04 inch, crater diameter of $0.144 \mathrm{inch}$, and crater depth of 0.313 inch.

Alternating-current spark-graphite rotating disk 0.492 inch in diameter and 0.2 inch thick.

Film: 35-millimeter Spectrum Analysis Nc. 1 emulsion, processed with $\mathrm{D}-19$ developer for 2 minutes at $20^{\circ} \mathrm{C}$, fixed for 5 minutes, rinsed in cold water, and air dried.

\section{DIRECT-CURRENT ARC METHOD}

Preparation of Matrix for Standards

To reduce one of the major problems in the spectrographic analysis of geological materials, namely the matrix effect, the composition of the matr:x powder for the field standards should approximate that of the sample (Ward and others, 1963). Ideally, a matrix of each rock type analyzed is needed, such as a gossan matrix, a silicate matrix, or a carbonate matrix. Preparation of a matrix for each rock type necessitates a knowledge of the composition of the samr'e before it can be analyzed, and the procedure is expensive and time consuming.

For reconnaissance geochemical studies, la rge numbers of samples are scanned for gross differences in concentrations, and a simple matrix is desirable. With only a slight loss of accuracy, a single, average matrix can be used (table 1). All compounds used in preparing the matrix are spectrographically pure except $\mathrm{SiO}_{2}$, which is obtained from natur:al quartz crystals. The quartz is crushed, pulverized to pass a 200-mesh screen, and washed free of impurities using the following procedure: 


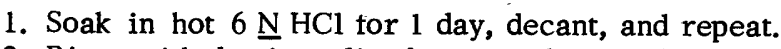

2. Rinse with demineralized water, alternately washing and decanting six times.

3 . Check for impurities.

4. Repeat complete procedure if necessary to remove all impurities.

Table 1. - Matrix used in direct-current arc method

Amount of compound used

for $100 \mathrm{~g}$ Equivalent

of matrix

(in grams) each element, usually the oxide or carbonate, to a predetermined amount of matrix to give the desired concentration of each element; the following are examples of amounts of various compounds used:

\begin{tabular}{lccc}
$\begin{array}{l}\text { Element } \\
\text { sought }\end{array}$ & $\begin{array}{c}\text { Compound } \\
\text { used }\end{array}$ & $\begin{array}{c}\text { Concentration } \\
\text { desired } \\
\text { (ppm) }\end{array}$ & $\begin{array}{l}\text { Amount of } \\
\text { compound } \\
\text { for 10 } \mathrm{g} \\
\text { of base } \\
\text { mixture } \\
\text { (in grams) }\end{array}$ \\
\hline $\mathrm{Ba}-\cdots--\mathrm{BaCO}_{3}$ & 5,000 & 0.0667 \\
$\mathrm{Sr}-\cdots-\mathrm{SrCO}_{3}$ & 5,000 & .0782 \\
$\mathrm{Mn}-\ldots-\mathrm{Mn}_{3} \mathrm{O}_{4}$ & 5,000 & .0644 \\
\hline
\end{tabular}

After the base mixture is prepared, stardards containing successively lower amounts of the elements are made using the reciprocal of the cube root of 10 $(0.464)$ as a dilution factor. For example, if the base mixture contains an element at a concentration of 100 ppm (parts per million), the succeeding: standards would contain the same element at concentrations of $46.4 \mathrm{ppm}, 21.5 \mathrm{ppm}, 10 \mathrm{ppm}, 4.64 \mathrm{ppm}$, end so forth (table 3 ). When the standard is used in a semiquantitative procedure, these numbers are rounded off to $50,20,10$, and 5 .

After each dilution, the standard is ground in an agate mortar for 15 minutes, then transferred to a clean glass vial containing several glass or plastic beads and shaken or mixed mechanically for 1 hour.

Table 2.-Concentrations (in parts per million) of elements in Field Stantard I

Elements in high-concentration standard

$\begin{array}{lll}\text { Dilution No. } \quad \mathrm{Cr}, \mathrm{Cu}, & \mathrm{Ni}, \mathrm{Pb}, \mathrm{Co}, \mathrm{Mo} \quad \mathrm{Ag}, \mathrm{Be},\end{array}$

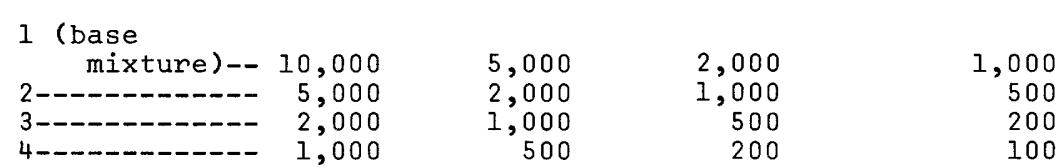

Elements in low-concentration (trace) standard

Billution No. Ti, Zn Ba, Mn, Sr La, v, Zr Cd, Cr, Cu, $\mathrm{Pb}$ B, Co, $\mathrm{M}, \mathrm{Ag}, \mathrm{Be}, \mathrm{Bi}$,

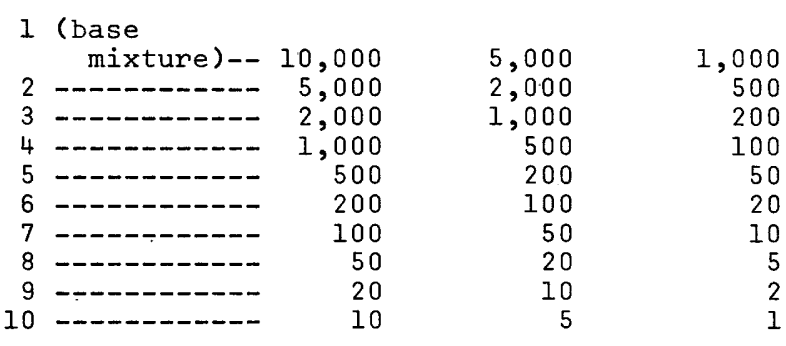

$\begin{array}{rrr}500 & 200 & 100 \\ 200 & 100 & 50 \\ 100 & 50 & 20 \\ 50 & 20 & 10 \\ 20 & 10 & 5 \\ 10 & 5 & 2 \\ 5 & 2 & 1 \\ 2 & 1 & .5 \\ 1 & .5 & .2 \\ .5 & .2 & .1\end{array}$


Table 3.-Dilution chart-three-step standards

Resulting
standard
(ppm)

1 (base

mixture)-- $\underline{X g}$ of metal oxide

$+\mathrm{Yg}$ of matrix
$=\frac{\mathrm{g}}{\mathrm{g}}$

100

$2 \ldots-1.857 \mathrm{~g}$ of $100 \mathrm{ppm}$

$+2.143 \mathrm{~g}$ matrix

$=4 \mathrm{~g}$

46.4

$3-1.857 \mathrm{~g}$ of $46.4 \mathrm{ppm}$

$+2.143 \mathrm{~g}$ matrix

$=4 \mathrm{~g}$

21.5

$4-1.857 \mathrm{~g}$ of $21.5 \mathrm{ppm}$

$+2.143 \mathrm{~g}$ matrix

$=4 \mathrm{~g}$

$5-1.857 \mathrm{~g}$ of $10 \mathrm{ppm}$

$+2.143 \mathrm{~g}$ matrix

$=4 \mathrm{~g}$

4.64

The importance of this step must be stressed, for unless thorough mixing is achieved, the succeeding lower concentrations will be inaccurate. The quantity of each standard should be kept low (2 to 4 grams) to help insure a good mix. Extreme care must also be taken to prevent contamination.

Field Standard II consists of two base mixtures, one containing the carbonates of calcium and magnesium and the other, the oxides of iron, arsenic, antimony, tungsten, and niobium. Gold is also added to the second base mixture. The high malleability of gold metal and the hygroscopicity of its available compounds make it impossible to obtain a reliable gold standard by adding gold directly to the mixture. To achieve an accurate and uniform distribution of gold in the standard, a solution of gold metal in aqua regia is evaporated onto a weighed amount of pure $\mathrm{SiO}_{2}$ matrix.
To prepare Field Standard II, both base mixtures are diluted with a pure $\mathrm{SiO}_{2}$ matrix using th $?$ same factor as for Field Standard I. After several dilutions, a weighed amount of one base mixture is adied to a weighed amount of the other and both are mired with the $\mathrm{SiO}_{2}$ matrix to $\mathrm{give}$ the desired concentrations (table 4), as shown in the following examples:

1. To make dilution 4 on table 4 , add $0.5 \mathrm{~g}$ (gram) of dilution 1 to $0.05 \mathrm{~g}$ of dilution 10 and $\mathrm{mix}$ both with $4.45 \mathrm{~g}$ of $\mathrm{SiO}_{2}$ matrix.

2. To make dilution 5 , add $0.5 \mathrm{~g}$ of dilution 2 . to 0.05 $\mathrm{g}$ of dilution 11 and mix with $4.45 \mathrm{~g}$ of $\mathrm{SiO}_{2}$ matrix.

Generally, geologic material that is high in magnesium and calcium is low in iron, and the material that is high in iron is low in magnesium and calcium. The standards listed in table 4 are set up to take account of this general rule.

\section{Operating Conditions}

Electrode gap spacing: 4 millimeters.

Exposure: 140 seconds.

Current: Initial excitation of 3 amperes increased to 11 amperes after 5 seconds.

\section{Analytical Procedure}

\section{Sample preparation}

Rocks: Crush the sample in a jaw crusher to $1 / 4-$ inch-size particles or less, split with an aliminum Jones Splitter, and pulverize in ceramic ball mills (Myers and Wood, 1960) to pass a 150-mesh screen.

Soils and stream sediments: Air dry the sample, sieve to pass an 80-mesh screen, split, and pulverize.

\section{Analysis}

Weigh 10 milligrams of the prepared sample, add 20 milligrams of pure graphite powder, andmix ir an aluminum weighing pan with a disposable wooden toothpick. Transfer the mixture into the cavity of a preformed electrode with the aid of an aluminum funnel

Table 4.-Concentrations of elements in Field Standard II

\begin{tabular}{lccrrr}
\hline Dilution No. & $\begin{array}{c}\text { Ca } \\
\text { (percent) }\end{array}$ & $\begin{array}{c}\mathrm{Mg} \\
\text { (percent) }\end{array}$ & $\begin{array}{c}\text { Fe } \\
\text { (percent) }\end{array}$ & $\begin{array}{c}\text { As, Sb, W } \\
(\mathrm{ppm})\end{array}$ & $\begin{array}{c}\mathrm{Nb} \\
(\mathrm{ppm})\end{array}$ \\
\hline $1-$ (base mixture) & - & - & 20 & 10,000 & 2,000 \\
$(\mathrm{ppm})$
\end{tabular}



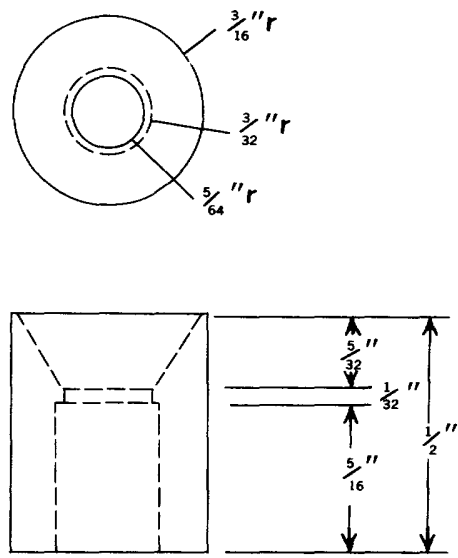

Aluminum funnel
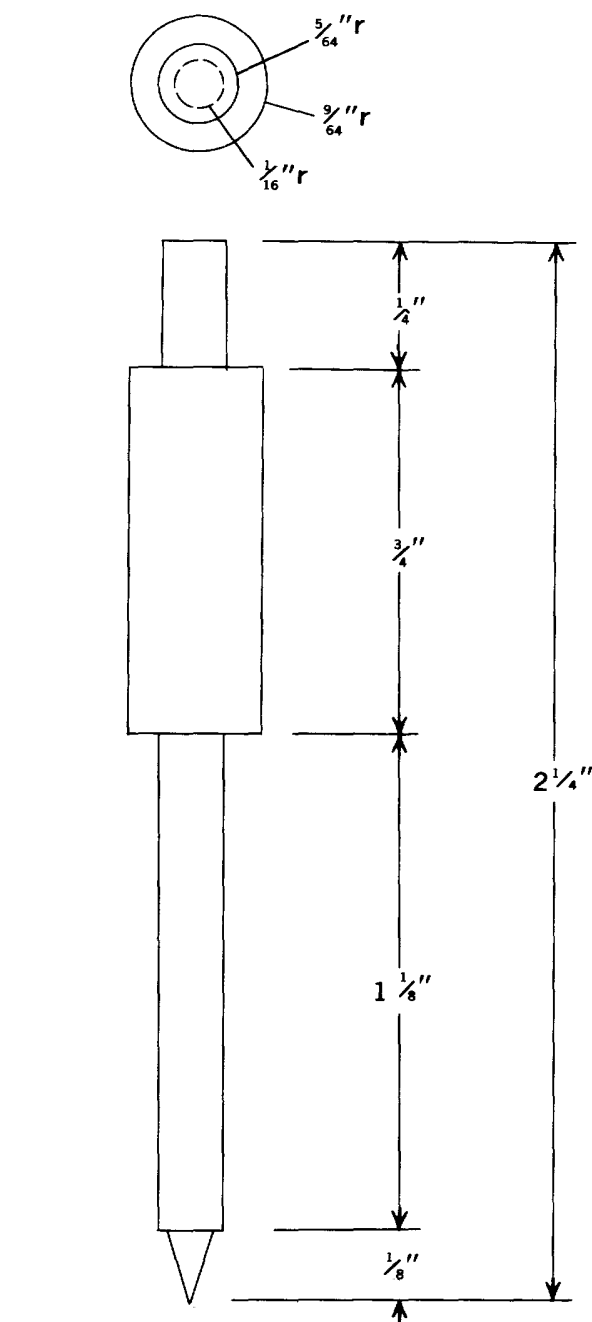

Aluminum venting rod

Figure 1.-Funnel and venting rod. Approximate scale $1: 2$. (fig. 1) and pack tightly with an aluminum venting rod (fig. 1). The resulting hole in the sample-graphite mixture affords a vent for extruding gas resulting from initial excitation. If a vent is not used, the sample and graphite should be preheated under an infrared lamp prior to excitation. Clamp the sample-carrying electrode and counter electrodes in the arc stand, initiate a current of 3 amperes by touching the electrodes together, open the arc gap, and burn the sample to completion at 12 amperes. Process the film and compare it visually with standard films using a X 20 comparator. The limits of determination and the wavelengths read are given in table 5 .

Table 5.-Limits of determination--directcurrent arc method

\begin{tabular}{|c|c|c|}
\hline Element & Wavelength (A) $1 /$ & $\begin{array}{l}\text { Lower limit of } \\
\text { determination } \\
\quad(\mathrm{ppm})\end{array}$ \\
\hline 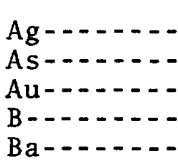 & $\begin{array}{ll}3280.7 & (3382.9)^{2 /} \\
2860.4 & (2780.2) \\
2675.9 & \\
2497.7 & \\
4554.0 & (2335.3)\end{array}$ & $\begin{array}{r}0.5 \\
200 \\
10 \\
10 \\
5\end{array}$ \\
\hline 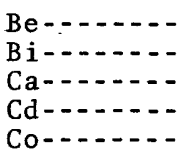 & $\begin{array}{l}3131.1 \\
3067.7 \\
3158.8 \\
3261.1 \\
3453.5\end{array}$ & $\begin{array}{r}1 \\
10 \\
500 \\
20 \\
5\end{array}$ \\
\hline 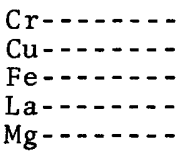 & $\begin{array}{l}4254.3 \\
3273.9 \\
3100.6 \\
3337 \cdot 5 \\
2781.4\end{array}$ & $\begin{array}{r}5 \\
2 \\
500 \\
20 \\
200\end{array}$ \\
\hline 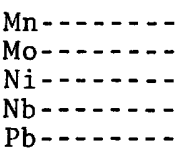 & $\begin{array}{l}2949.2 \\
3170.3 \quad(3193.9) \\
3414.7 \\
3163.4 \\
2833.0\end{array}$ & $\begin{array}{r}10 \\
5 \\
2 \\
10 \\
10\end{array}$ \\
\hline 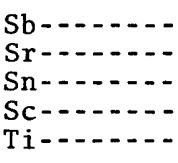 & $\begin{array}{ll}2877.9 & \\
4607.3 & (3464.4) \\
3175.0 & (2839.9) \\
3353.7 & \\
3168.5 & \end{array}$ & $\begin{array}{r}100 \\
50 \\
10 \\
5 \\
10\end{array}$ \\
\hline 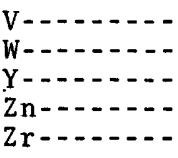 & $\begin{array}{l}3102.3 \quad(3183.9) \\
2946.9 \\
3327.8 \\
3345.0 \\
3279.2\end{array}$ & $\begin{array}{r}10 \\
50 \\
10 \\
200 \\
20\end{array}$ \\
\hline
\end{tabular}

1/From Meggers, Cor1iss, and Scribner (1961).

2/ Numbers in parentheses are alternate wavelengths used.

\section{ALTERNATING-CURRENT SPARK METHOD}

\section{Preparation of Matrix Solution for Standards}

The matrix solution for the standards is obtained by dissolving the nitrates of the five elements listed in table 6 in a 1:1 nitric acid solution. The concentration, 
Table 6.-Matrix solution-a1ternating-current spark method

\begin{tabular}{lr}
\hline Element & Concentration (percent) \\
\hline Fen- & 5.0 \\
$\mathrm{Ca}$ & 1.0 \\
$\mathrm{Na}$ & 1.0 \\
$\mathrm{Mg}$ & 1.0 \\
\hline
\end{tabular}

of these elements in the solution is approximately equal to their average concentration in rocks and soils. Although $\mathrm{SiO}_{2}$ and $\mathrm{Al}_{2} \mathrm{O}_{3}$ constitute about 75 percent of all geologic material, they are not added to the matrix solution because both are present only in minute concentrations in the sample solutions; during sample preparation, $\mathrm{SiO}_{2}$ is removed by hydrofluoric acid treatment, and $\mathrm{Al}_{2} \mathrm{O}_{3}$ is very insoluble in the acid used in the leaching step.

\section{Preparation of Standard Solutions}

Two separate standard solutions are used (table 7). For standard solution 1 , the $n$ it $r$ a t e s of silver, cadmium, copper, nickel, and zinc are weighed to give the desired concentrations and then are dissolved in the matrix solution. Standard solution 2 contains arsenic, gold, bismuth, cobalt, molybdenum, palladium, platinum, antimony, and tin; the gold, molybdenum, and antimony are put in solution by dissolving the metals in aqua regia, and this solution is added to the matrix solution containing the rest of the elements. By subsequent dilutions of these two $s t a n d a r d s$ with the matrix, three-step standards are obtained with concentrations ranging from 5,000 to $0.2 \mathrm{ppm}$.

Table 7.- Standard solutions-alternatingcurrent spark method

\begin{tabular}{|c|c|c|}
\hline Element & Compound used & $\begin{array}{l}\text { Concentration } \\
\text { range (ppm) }\end{array}$ \\
\hline \multicolumn{3}{|c|}{ Standard solution 1} \\
\hline 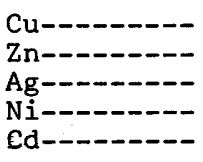 & $\begin{array}{l}\mathrm{Cu}\left(\mathrm{NO}_{3}\right)_{2} \cdot 2 \mathrm{H}_{2} \mathrm{O} \\
\mathrm{Zn}\left(\mathrm{NO}_{3}\right)_{2} \cdot 6 \mathrm{H}_{2} \mathrm{O} \\
\mathrm{AgNO} \\
\mathrm{Ni}\left(\mathrm{NO}_{3}\right)_{2} \cdot 6 \mathrm{H}_{2} \mathrm{O} \\
\mathrm{Cd}\left(\mathrm{NO}_{3}\right)_{2} \cdot 4 \mathrm{H}_{2} \mathrm{O}\end{array}$ & $\begin{array}{l}5,000-2 \\
5,000-20 \\
500-0.2 \\
500-2 \\
500-20\end{array}$ \\
\hline \multicolumn{3}{|c|}{ Standard solution 2} \\
\hline 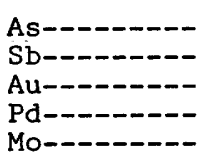 & $\begin{array}{l}\mathrm{K}_{3} \mathrm{AsO}_{4} \\
\mathrm{Sb} \text { (metal) } \\
\mathrm{Au}(\text { metal) } \\
\left(\mathrm{NH}_{4}\right)_{2} \mathrm{PdCl}_{4} \\
\mathrm{Mo} \text { (metal) }\end{array}$ & $\begin{array}{l}5,000-20 \\
5,000-50 \\
500-0.2 \\
500-1 \\
500-5\end{array}$ \\
\hline 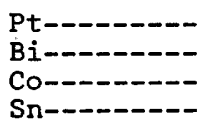 & $\begin{array}{l}\mathrm{H}_{2} \mathrm{PtCl}_{6} \cdot 6 \mathrm{H}_{2} \mathrm{O} \\
\mathrm{Bi}\left(\mathrm{NO}_{3}\right)_{3} \cdot 5 \mathrm{H}_{2} \mathrm{O} \\
\mathrm{Co}\left(\mathrm{NO}_{3}\right)_{2} \cdot 6 \mathrm{H}_{2} \mathrm{O} \\
\mathrm{SnCl}_{2} \cdot 2 \mathrm{H}_{2} \mathrm{O}\end{array}$ & $\begin{array}{l}500-5 \\
500-10 \\
500-10 \\
500-10\end{array}$ \\
\hline
\end{tabular}

\section{Operating Conditions}

Electrode gap spacing: 2 millimeters.

Exposure: 105 seconds.

Inductance: $\mathbf{4 0}$ microhenrys.

Capacitance: 0.005 microfarad.

Resistance: Residual.

Current: 5 amperes.

Break per half cycles: Four.

Disk speed: 10 revolutions per minute.

\section{Analytical Procedure}

Transfer $1.5 \mathrm{~g}$ of ground sample to a $30-\mathrm{ml}$ (milliliter) teflon beaker containing $3 \mathrm{ml}$ of concentrated hydrofluoric acid. Swirl to mix and let stand ir a hood for at least 18 hours. If an excess of hydroflucric remains, heat gently to dryness, cool, add $4 \mathrm{ml}$ aqua regia, place on a vibrating hotplate, and heat $\varepsilon+100^{\circ} \mathrm{C}$ for 1 hour. Cool, transfer to a $10 \times 75$-millime+er culture tube, wash with a minimum amount of derrineralized water, centrifuge, decant to a graduated test tube, and dilute to $3 \mathrm{ml}$ with water. Mix and transfer to a No. 00 porcelain boat. Place on rotating disk assembly stage and excite.

A good exhaust system for the arc stand is necessary to remove fumes from the vaporization of the acidic solution on the disk. The platform, the electrode holders, and the interior of the arc stand stould be carefully cleaned to prevent corrosion.

After excitation of the sample solutions is conplete, the film is processed and compared to the standard films in a comparator with a X 20 magnification. The limits of determination and the wavelengths read are given in table 8 .

Table 8. - Limits of determination-a1ternating-current spark method

\begin{tabular}{|c|c|c|}
\hline Element & Wavelength1/ & $\begin{array}{l}\text { Lower limit of } \\
\text { determination } \\
\quad(\mathrm{ppm})\end{array}$ \\
\hline 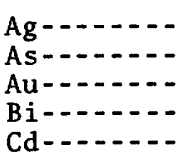 & $\begin{array}{ll}3280.7 & (3382.9)-2 / \\
2860.4 & \\
2675.9 & (2427.9) \\
3067.7 & \\
3261.1 & \end{array}$ & $\begin{array}{l}0.2 \\
20^{.2} \\
10^{\circ 2} \\
20\end{array}$ \\
\hline 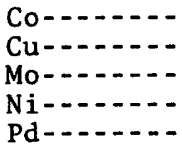 & $\begin{array}{ll}3453.5 & \\
3273.9 & \\
2871.5 & (2848.2) \\
3414.7 & (3101.9) \\
3242.7 & (3404.6)\end{array}$ & $\begin{array}{l}10 \\
5 \\
2 \\
1\end{array}$ \\
\hline 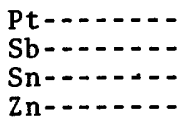 & $\begin{array}{ll}2659.4 & (3064.7) \\
2877.9 & \\
3034.1 & (3175.0) \\
3302.6 & (3345.0)\end{array}$ & $\begin{array}{r}5 \\
50 \\
10 \\
20\end{array}$ \\
\hline
\end{tabular}

1/From Meggers, Cor1iss, and Scribner (1961).

$\underline{2} /$ Numbers in parentheses are alternate wavelengths used. 


\section{CONCLUSIONS}

The direct-current arc method allows a great number of determinations over a wide range of geologic samples. It is especially useful as a reconnaissance tool. With this method a team of four men can log, prepare, weigh, excite, read, and report at least 100 rock or soil samples per day.

The alternating-current spark method is more cumbersome and is better suited to fixed laboratory operations, but it also may be performed in the field. A team of two men can analyze 30 to 40 samples per day.

The question of which method to use depends on the nature of the geologic material, the elements sought, the limits of determination, the number of samples to be analyzed, and the amount of time available.

\section{REFERENCES}

Canney, F. C., Myers, A. T., and Ward, F. N., 1957, A truck-mounted spectrographic laboratory for use in geochemical exploration: Econ. Geology, v. 52, no. 3, p. 289-306.
Meggers, W. F., Corliss, C. H., and Scribner, B. F., 1961, Tables of spectral-line intensities: Natl. Bur. Standards Mon. 32, pt. 1, 473 p.

Myers, A. T., Canney, F. C., and Dunton, P. J., 1956, Semiquantitative spectrographic aralysis in a truck-mounted laboratory for geoch emical exploration-a preliminary report [abs.]: Spectrochim. Acta, v. 8, no. 2, p. 110.

Myers, A. T., and Wood, W. H., 1960, Ceramic mills in a paint mixer for preparation of multiple rock samples: Appl. Spectroscopy, v. 14, p. 136-137.

Oda, Uteana, Myers, A. T., and Cooley, E. F., 1958, A field method of spectrographic an-lysis for use in geochemical exploration-an improved technique lab: Anal. Chemistry and Appl. Spectroscopy Conf., Pittsburgh, Program, p. 46.

Ward, F. N., Lakin, H. W., Canney, F. C., and others, 1963, Analytical methods used in genchemical exploration by the U.S. Geological Surv 9y: U.S. Geol. Survey Bull. 1152, 100 p. 